\title{
Appers pedagógicos e atratores visuais: haverá uma inteligên- cia conectiva em construção?
}

\author{
Cíntia I. Boll ${ }^{1}$, Ricardo C. Lopes ${ }^{2}$, Nádila Albuquerque Luchini $^{1}$ \\ 'Professora no Programa de Pós-Graduação Educação em Ciências: Química da Vida e \\ Saúde - Associação de IESs - Universidade Federal do Rio Grande do Sul (UFRGS) \\ Caixa Postal 15.064 - 91.501-970 - Porto Alegre - RS - Brazil \\ Doutorando em Sociologia - Universidade Federal do Rio Grande do Sul - Porto Ale- \\ gre, Brazil. \\ 'Licencianda em Pedagogia \\ Universidade Federal do Rio Grande do Sul (UFRGS) - Porto Alegre, RS - Brazil \\ cintiaboll@gmail.com, rshicardoehotmail.com, nadila.lu- \\ chinil4@gmail.com
}

\begin{abstract}
The present work deals with a trans-generational analysis of pedagogical applications created by graduates in the Brazilian platform named Application Factory. We will analyze the presence of attractors (CANEVACCI, 2008) in what we will call third generation APP under the collective intelligence approach (LÉVY, 2010) from seven versions of Apps, listed throughout this study. Thus, at first, we will define the concept of attractor to, in a second moment, analyze this empirical environment. It is possible to believe that a connective intelligence - that emerges these pedagogical applications - contributes to signify educational processes in times of digital culture.
\end{abstract}

Resumo. O presente trabalho trata de uma análise transgeracional de aplicativos pedagógicos criados por licenciandos na plataforma brasileira nomeada de Fábrica de Aplicativos. Analisaremos a presença de atratores (CANEVACCI, 2008) no que denominaremos como Apps da terceira geração sob o enfoque de uma inteligência coletiva (LÉVY, 2010) a partir de sete versões de Apps, listados ao longo do estudo. Assim, em um primeiro momento, definiremos o conceito de atrator para, em um segundo momento, analisar o ambiente empírico. É possível crer que uma inteligência conectiva - que emerge destes aplicativos pedagógicos - contribua para significar os processos educativos em tempos de cultura digital.

\section{Introdução}

Para Lévy (1998) “... a inteligência coletiva não é um conceito exclusivamente cognitivo" (p.26) e está, em essência, no processo criador (p.69) de quem pensa em si e no mundo que o envolve. Segundo Lévy, o intelectual coletivo se manifesta a partir de suas experiências no aprendizado individual dos processos cognitivos, sociais e afetivos que, hoje também possíveis de serem reunidos digitalmente, permitem a observação das relações amigáveis, profissionais e políticas (p.99-100). Neste trabalho, estudamos se a 
convivência formal para construção pedagógica de aplicativos (APP) para mídias móveis em uma disciplina de graduação na licenciatura presencial pode resultar ao que definiremos como inteligência conectiva pois que acreditamos que a intensidade do convívio no semestre se enuncia na criação autoral.

Nosso universo empírico são os aplicativos desenvolvidos por alunos de graduação de uma disciplina na plataforma brasileira Fábrica de Aplicativos como requisito de aprovação parcial. A amostra foi definida como de terceira geração pois que a cada semestre a relação entre discentes e tecnologias digitais se apresenta modificada, lançando sobre nós outros olhares pois que as mesmas observações não são possíveis de serem feitas com as novas produções dos alunos, obrigando-nos a reformular hipóteses e significados. Cremos que, neste novo movimento, um outro entrelaçamento se apresenta em direção a uma típica inteligência conectiva entre os licenciandos e professor, para além de coletiva. Portanto, nosso percurso de observação foi o de analisar cada aplicativo a fim de tentar encontrar entre eles algum outro processo criativo deliberadamente alocado pelo(s) aluno(s) em seu(s) apps, funcionando como potentes comunicadores conectivos dos conteúdos estudados na disciplina.

Nesse primeiro momento, portanto, contextualizaremos nosso estudo com os APP e a Fábrica de Aplicativos. Num segundo momento, focaremos na revisão conceitual e, por fim, iremos propor outros olhares sobre esses novos apps.

\section{Os APP e a Fábrica de Aplicativos}

Os produtores dos APP, os appers como são chamados os criadores de aplicativos para dispositivos móveis, hoje também licenciandos e professores, têm em suas escolhas digitais de sons, textos e imagens a serem conectadas aos apps, apenas como parte de sua criação comunicativa. Os appers pedagógicos entrelaçam e potencializam às suas escolhas especialmente os conteúdos estudados na disciplina, conectando pedagogicamente aos apps uma típica ação comunicativa em tempos de cultura digital e móvel. Muito mais que conteúdos essa conexão de que falamos é aquela onde a estética dessa criação está para além criador de aplicativos educacionais.

Os aplicativos desenvolvidos na disciplina e disponíveis publicamente no repositório do site Cultura Digital e Mídias Móveis $(<$ https://www.ufrgs.br/culturadigitalmidiasmoveis $/>)$ se apresentam para, também, outros futuros licenciandos que vierem a cursar a disciplina em outros semestres como modelos, como ideias, como propostas estéticas de uma criação autoral. Os apps não como apenas usos e/ou estudos mas como produtor de sentidos a partir de uma posição enunciativa própria, onde cada novo busque capturar um olhar, seja do grande publico em geral, seja de um outro atento e cuidadoso licenciando espect-autor (BOLL, 2013, p.57):

\footnotetext{
$\mathrm{Na}$ cultura participativa presente em uma narrativa transmidiática, sustentada por seus múltiplos universos ficcionais que pers eguempedaços de his tórias cada vez mais em canais midiáticos diferentes, o que requer uma performance muito mais conetiva dos multivíduos espect-autores, parece que uma narrativa redundante, que não oferece sentidos para entretenimento, cada dia tem menos espaço comunicativo na Cultura Digital. A narrativa transmidiática sustentada comercial e economicamente pelas mídias digitais se apresenta com um forte componente imagístico que requer um olhar atento e cuidadoso para compreender os detalhes na produção dos sentidos na composição da arte da construção de universos. Os detalhes da narrativa são, tal como os atratores para
} 
VI Congresso Brasileiro de Informática na Educação (CBIE 2017)

Anais do XXIII Workshop de Informática na Escola (WIE 2017)

um Fetiche Visual, acoplados para seduzir e encenar enigmas silenciados. Alimentar imaginações, possibilidades cognitivas de criação e entusiasmo.

Considerando que cada espectautor, enquanto interlocutor (BAKHTIN, 1988), leitor-autor (AXT, 2008) e espect-ador (CANEVACCI, 2001) de seus processos comunicativos, assume uma posição auto-organizada nessa produção, a estética dessa criação quando se apresenta no app de um licenciando se oferece para que uma inteligência conectiva ali se manifeste. Na esteira do que Lévy (2010) define como inteligência coletiva, construída a partir da interação entre comunidades virtua is, entendemos que essa interação a partir de apps pedagógicos deva garantir uma típica comunicação em tempos de cultura digital para além das imagens, sons e textos. Os appers pedagógicos devem focar especialmente possibilidades cognitivas de aprendizagem entre seus usuários.

Os appers pedagógicos intensificam o poder enunciativo quando outros autores se sentem convidados a participar, assumindo eles mesmos sua posição pela busca de sentido. Quando appers pedagógicos se movimentam nessa direção, pela busca de outras possibilidades cognitivas de criação e entusiasmo, um estilo singular enunciativo se apresenta acoplado à atratores em forma de textos, sons ou imagens, agregando às possibilidades comunicativas múltiplas conexões:

\begin{abstract}
Então, a cultura e a comunicação digital, que colocam em crise esta perspectiva coletiva, conseguem afirmar o processo conectivo que significa que a individualidade, que prefiro chamar de multivíduo se multiplica, se amplia, explode. Uma multiplicidade de eus no corpo subjetivo. Essa condição múltipla favorece a proliferação dos eus o que acaba por desenvolver outro tipo de identidade, fluida e pluralizada, que coloca, potencialmente em crise, as formas perversas e tradicionais do dualismo. (CANEVACCI, 2009-a, p.9).
\end{abstract}

$\mathrm{O}$ atrator, um conceito importante neste processo enunciativo para um apper pedagógico, se conecta à ideia de que mais do que indivíduos coletivos somos multivíduos conectivos. Fluidos e pluralizados, nos movimentamos pela busca dos enunciados que nos conectem, "enunciados esses que têm tornado cada vez mais íntima a própria relação comunicativa entre o que é visível e o que é vivido em cada multivíduo, como se fosse e não fosse ao mesmo tempo um fragmento dado de fora, pois que a ele esse enunciado também pertence" (BOLL, 2013, p.24). Enunciados que também podem ser meus nessa relação singular e autoral da construção do conhecimento em tempos de cultura digital e móvel, para além de um lócus tradicional de ensino quadro-livro-giz.

$\mathrm{Na}$ busca pela enunciação comunicativa de que falamos os appers pedagógicos incluem atratores para que a criação se apresente e a inteligência conectiva, necessária nesse processo, se destaque. A criação, então, se estrutura nessa produção de um estilo singular comunicativo tensionando esse ponto de encontro entre todos: o atrator. De acordo com Canevacci (2005) sentidos e vozes coexistem em um mesmo multividuo na interatividade dos textos midiáticos, comunicação e consumo. Em sendo a Fábrica de Aplicativos (<http://fabricadeaplicativos.com.br/ >) uma plataforma web brasileira de criação e compartilhamento de aplicativos mobile, não exigindo conhecimento de linguagem de programação, os appers pedagógicos são convidados a criar seus próprios apps, inserindo imagens (para a abertura, cabeçalho e fundo) em álbum de fotos, galeria de áudios, lista (textos) e mapa e outros recursos oferecidos preferencialmente na versão gratuita. 
VI Congresso Brasileiro de Informática na Educação (CBIE 2017)

Anais do XXIII Workshop de Informática na Escola (WIE 2017)

\section{O atrator visual e imagens performativas}

Brown (2007) apresentou a importância da sinergia entre os participantes em uma ação comunicativa também em ambientes digitais, pois que, diz ele, “[...] na medida que conversamos em conjunto nos tornamos capazes de acessar uma sabedoria maior que se encontra apenas no coletivo"(p.14). Enquanto conversamos, o atrator, uma espécie de aglutinador no processo, se apresenta sinergicamente em uma relação sistêmica e comunicacional ativando a capacidade de auto-organização ao que Brown define como "sinapses da mente do grupo" (p.131).

Considerando a "[...] reflexão a respeito do poder da conversação e da sabedoria coletiva [...]", narrada no livro O World Café, Brown afirma que o atrator presente na troca comunicativa é resultante das conversações significativas e estratégicas, que, de uma forma ou de outra, todos temos a capacidade de trabalhá-las juntos, independente dos “...métodos populares que usamos atualmente para pré-identificar e pré-julgar pessoas" (2007, p.13-14). Nessa experiência compartilhada (inclusive on-line, através de chat) entre milhares de pessoas de diferentes partes do mundo, todos os participantes foram convidados a sentarem-se em uma mesa de café, a fim de que se movessem, “...de mesa para mesa, levando as ideias sementes de uma mesa do Café para outra, eles se ligam e unem seus pensamentos, ideias e perguntas" (p.131). Para a autora, as perguntas que movem os pensamentos, as ideias e os desejos de compartilhar são "os verdadeiros atratores da aprendizagem dialogal e [da] inteligência coletiva" (p.135).

Para Brown (2007), as perguntas "poderosas", ao que nós entendemos como se em algum momento no processo cognitivo pudessem ser enigmas silenciados, alimentos de imaginações, possibilidades cognitivas de criação e entusiasmo, funcionam como perturbações que, numa rede ativa de comunicação, geram um ponto de instabilidade que pode se manifestar em tensão, caos, incerteza ou crise, onde:

[...], o sistema pode entrar em colapso ou pode romper uma barreira e entrar num novo estado de ordem, caracterizado pela novidade e por uma experiência de criatividade que muitas vezes parece mágica (CAPRA, p.128).

Assim, enquanto um conceito fundamental para Capra (2005) que entende a importância do atrator quando relacionado a um mundo vivo, sistêmico e mutante justamente pela sua existência como catalisador, numa criação comunicativa é o atrator que passa a tensionar, a fixar olhares e empoderar sentidos, movimentando desejos que também se traduzem em "[...] sensações de incerteza e de perda do controle sobre as coisas, sensação essa que é no mínimo, incômoda" (p.130). Pois é nesse lugar - o do "suspenso", o do "vácuo" - que se encontra o conceito de atrator visual em Massimo Canevacci (2008), um conceito-sentido em imagens performativas que cada dia mais estão dispostas material e imaterialmente na cultura digital (p.13) como se a todo momento pudesse haver, em uma alusão a Brown, "convidados" sentados à mesa de um café negociando sentidos:

[...] os fetichismos contemporâneos - e as mercadorias visuais- são atratores visuais com "alto valor fetish", que absorvematenção nos seus movimentos inter e intraespaciais." (BOLL, 2013, p. 14)

Para Canevacci (2008, p. 15), os atratores visuais quando em composição com imagens performativas concentram Fetiches Visuais tais como se fossem “... fragme ntos simbólicos que atravessam os modos perceptíveis de um olhar que de modo nenhum é 
VI Congresso Brasileiro de Informática na Educação (CBIE 2017)

Anais do XXIII Workshop de Informática na Escola (WIE 2017)

ingênuo ou manipulável, embora condicionado à decodificação", daí o seu eminentemente caráter cultural.

Os atratores visuais se impõem, absorvem e fixam os nossos olhares. Eles podem ser potentes enigmas que disseminam insinuações e atravessam identidades (idem, p. 3942) no desejo de se conectar nesse típico processo comunicativo contemporâneo. Esses atratores dos quais falamos, quando em composição comunicativa, se apresentam tal como se fossem produtos ideológicos que acabam por reverberar na cultura do cotidiano, também digital, em linguagens típicas de um público jovem que parece "des-cobrir" seus próprios fetiches. Como parte de desejos comunicativos em tempos de cultura digital, os fetiches visuais enunciam infinitas possibilidades de produção de sentidos, (dis)simulados e (dis)farçados em estilos discursivos que se sobrepõem às variáveis enunciativas que, de atrator a atrator, valoram just in time acentos ideológicos, jeitos e trejeitos de ensinar e aprender.

Os Fetiches Visuais, quando existentes, se tramam aos atratores visuais interpelados pelas entonações dos enunciados digitais, que segundo Canevacci, atuam "[...] nas possíveis liberações múltiplas do eu ('eus') " (p.93), comunicando e seduzindo espectadores atentos:

Os atratores são policêntricos e polimorfos, sincréticos e fetiche. Os atratores encenam enigmas silenciados: são enigmas somatizados para serem apresentados, em um ambiente particular, a um público específico. (...) O atrator é, portanto, um espaço-bifásico (ou espaço-de-trânsito) que exerce um appeal erótico em direção aos corpos cheios-de-olhos, atraindo-se para si (CANEVACCI, 2008, p.40-41).

Tal como num jogo erótico, os Fetiches Visuais se apresentam em imagens performativas pelas criações dos appers pedagógicos para causar espanto e atenção instantânea. Os Fetiches Visuais quando presentes nos appers pedagógicos capturam nosso olhar pois que entrelaçados aos atratores há uma ruptura pedagógica que só um espectautor atento poderá apreciar. Assim como Jenkins (2008) acreditamos que a importância de um atrator na relação comunicativa em tempos de cultura participativa, ao mesmo tempo em que atrai, o atrator ativa culturalmente porque ele “... cria uma base comum entre as diversas comunidades (...) impulsionando sua decifração, especulação e elaboração" (p.135). E essa carga ativada é exatamente o que entendemos como inteligência conectiva.

Ainda para Jenkins (2008) um filme como Matrix (1999) pode ser concomitantemente um atrator e um ativador cultural pois que o espectador é potencialmente envolvido, participante e interagente nos seus mais variados suportes midiáticos. Na composição do conceito de "atrator cultural", Jenkins discute com Lévy (1999, p.117) sobre esse desejo de movimento aglutinador especialmente entre fãs e críticos quando estão em busca da construção de significados (JENKINS: 2008, p.330). E é nesse desejo pela construção de significados que, na relação discursiva, o espectautor se prepara para apresentar sua própria voz, dando continuidade à corrente dialógica iniciada. É o espectautor atento que analisando, assistindo e optando- não necessariamente nessa ordem, cria seu próprio e singular estilo: a inteligência conectiva existe em potência na criação mas é vivida apenas na relação discursiva dialógica. $\mathbf{E}$ é no interdiscurso que determinada enunciação nessa estética digital, carregada pelo atrator, comporta-se como voz que não é de um indivíduo, mas de "um" "eu" multivíduo. 
VI Congresso Brasileiro de Informática na Educação (CBIE 2017)

Anais do XXIII Workshop de Informática na Escola (WIE 2017)

Para nós a inteligência conectiva existe exatamente quando o atrator, seja em texto, som ou imagem, inclui infinitos estilos capturados pelos discursos dialógicos são compartilhados pelo appers pedagógicos. Quando o atrator na composição do aplicativo pelos appers pedagógicos tende a convergir sentidos implicados aos contextos estudados na disciplina, convidando a todos a apreciarem intencionalidades na composição do estilo, é possível crer que uma inteligência conectiva emersiva desse processo confirme um fetiche visual enquanto produção estética. Bakhtin (1988, p.87) apresenta a estética na relação com a obra literária tal como se fosse um jogo de intenções verbais que ali se encontram como vozes:

\begin{abstract}
As relações do sentido, dentro de um enunciado (ainda que fosse potencialmente infinito, como no sistema da ciência, por exemplo), são de ordem factual-lógica (no sentido lato do termo), ao passo que as relações do sentido entre enunciados distintos são de ordem dialógica (ou, pelo menos, têm um matiz dialógico). O sentido se distribui entre as diversas vozes. Importância excepcional da voz, da individualidade (BAKHTIN: 2000, p.342).
\end{abstract}

Portanto, a possibilidade dialógica - sempre multidirecional - acontece nesse vácuo produzido pelos atratores visuais em direção a uma inteligência conectiva, acontece nessa tensão dos sentidos entre todas as vozes participantes. O atrator visual se apresenta em uma imagem performativa tal como um elemento simbólico que busca intencionalmente "deter" e unir o olhar do multivíduo impelindo-o a produzir sentidos. Portanto, os appers pedagógicos são tensionados e tensionam ao mesmo tempo a inteligência conectiva de todos os espectautores, professores, tutores e/ou monitores e alunos sempre em busca de seu próprio estilo na criação do seu conhecimento.

\title{
4. A produção de estilo e o encontro dos atratores visuais em tempos de Cultura Digital: o app como forma e o Fetiche Visual como tema
}

Pela quantidade de textos, sons e imagens compartilhados através dos aplicativos para mídias moveis, tais como WhatsApp, Telegram, Messenger e outros, corpo e metrópole estão cada dia mais acoplados a uma típica comunicação em tempos de cultura digital onde a palavra é carregada sempre e para alem de suas letras (ou ausência delas). Enquanto algumas escolas tentam anular a produção de estilo em tempos de cultura digital oferecendo um lócus pedagógico entre provas e trabalhos também uniformes e padrões, Canevacci (2008) nos ajuda a pensar essa vida que tem a própria pele como não-limite. Pele essa que pelos piercings, tatuagens e outros aparatos comprovam que nem a pele pode ser "limite", muito menos (tudo) o que está sobre ela...

Canevacci nos afirma que nem só a pele mas o próprio corpo não é "natural", no sentido cultural do termo. Cada cultura preenche o indivíduo com sinais e símbolos típicos de seu tempo mas sempre haverão tentativas de que estilos se transponham a limites para além de fronteiras pois que "[...] quando a pele transpõe seus limites, ela se liga aos tecidos 'orgânicos' da metrópole" (idem, p.18). Então, parece-nos que enquanto (ainda) se tenta padronizar padrões de estilos outras fronteiras, hoje nos parece as que se movimentam digitalmente, até então inimaginadas insistem em sugerir que se criem estilos. E a cultura então cada dia mais móvel e digital intensifica essa produção.

Professores, tutores e/ou monitores e alunos, ou simplesmente os agentes comunicativos desse processo ao que definimos como espectautores, implicados nesse acontecimento, se apresentam com os tecidos digitais da metrópole, diríamos nós, com os textos, sons e imagens criados e recriados como parte de seu discurso estético. Nessa 
parceria com a Cultura Digital peles e corpos acoplados ao desejo comunicativo ficam registrados em rastros nessa que é hoje a grande metrópole da internet. E essa exposição registrada, enunciada, se movimenta em direção às múltiplas vozes envolvidas para se concentrar, definitivamente, numa singularidade enunciativa cada vez mais facilitada pelos aplicativos em mídias móveis: os Fetiches Visuais.

De posse a essa singularidade, volvemo-nos aos espaços escolares na produção de aplicativos numa disciplina enquanto acontecimentos ético-estéticos - pois que ali se encontram registros em textos, sons e imagens para serem consumidos enquanto nãomercadoria, não-conteúdo e não-produto. Sem síntese, com foco disperso justamente pelos atratores visuais. Em metamorfose: tal como um casulo tenso que explode colorido e que no processo se descobre. Apps enquanto registros autorais, portanto, dialógicos e digitalmente compartilhados.

O aluno, hoje espectautor e apper pedagógico, da disciplina de graduação se envolve em novas formas de "publicação" contemporâneas e ao mesmo tempo o faz com a benção do (atual) clérigo: o professor. Esse, o professor e o tutor/monitor da disciplina, quando existentes, são também agentes comunicativos dessa autoria dialógica, o Fetiche Visual, do qual falamos. Espectautores lhe dão ouvidos pois que - enfim - descem da arena e parecem querer criar um "outro" participante nesse processo comunicativo digital contemporâneo- o estilo. Um estilo, afetado pelas relações histórico-sociais que os constituem, que tem o dialogismo como fronteira comunicativa.

$\mathrm{O}$ apper pedagógico tem se apresentado um pouco nervoso nas atividades que the são dirigidas porque ele conhece as dimensões técnicas e criticas dos estudos das mídias ao que Boll se refere (2013), mas parece desconhecer essa parte da criação, o Fetiche Visual, o que the (pode) causa(r) um certo mal estar "pedagógico". A metodologia que o aluno da disciplina conhece se justifica pelo fim ou pelo começo: não há entrescomeços e entres-fins, ou seja, não há paradas contemplativas para serem conhecidas tal como poderia nos ajudar a pensar Bergson (2006), diz ele que é preciso restituir ao movimento sua mobilidade, à mudança sua fluidez, ao tempo sua duração a fim de que revele-se, por fim, "criação continua, jorro ininterrupto de novidade"(p.11). A técnica e a critica, como foco e a apreciação e contemplação, jamais!

As possibilidades criadoras entrelaçadas aos dispositivos cada vez mais moveis nos apresentam fronteiras cada vez mais dificeis de serem visualizadas apenas do ponto de uma dimensão técnica e critica (especialmente hoje) na criação (especialmente digital) dos trabalhos escolares. A apreciação e a contemplação oferecidas pelos Fetiches Visuais na criação pelos então appers pedagógicos podem nos apresentar outras singularidades em seus elementos constituidores, tais como os tecidos orgânicos de uma metrópole viva e comunicativa que Canevacci (2008) nos acena.

A composição estética tem em essência o desejo da contemplação comprometida com todos os participantes da narração, nunca imobilizada em inícios, fins e meios e sempre em movimento, na fronteira das paradas virtuais sugeridas pelos entres: entreprofessor, entre-aluno, entre-espectautor. A composição estética de um Fetiche Visual, portanto, é criação.

Para Canevacci (2008), o Fetiche Visual se apresenta numa comunicação ideológica como que em suspenso, aguardando para ser, com a ajuda de atratores, ativado por "perguntas", enquanto sentidos dos espectadores, espect- 
VI Congresso Brasileiro de Informática na Educação (CBIE 2017)

Anais do XXIII Workshop de Informática na Escola (WIE 2017)

atores ou espect-autores participantes. O Fetiche Visual, enquanto conteúdo de uma comunicação ideológica, é híbrido. Ele foge e flui neste lugar da criação: ele se transforma visualmente para receber o multivíduo. É na relação entre multividuos espect-atores que o Fetiche Visual se estabelece. (BOLL, 2013, p.64)

E alguns dos apps criados por nossos alunos um elemento dialógico concentrou os olhares de todos entres nessa composição e fez emergir o que definimos aqui como "inteligência conectiva" para que, enfim, o Fetiche Visual se apresentasse para ser apreciado. O Fetiche Visual se transformou visualmente para receber os multivíduos para compor a ideia do app, para compor o cenário do app, para compor a escrita do app pelo elemento dialógico de uma inteligência conectiva. Criando cenários, criando tecidos digitais-orgânicos que se tramam em conteúdos e estudos desenvolvidos no semestre estilizados em atratores cuidadosamente ali expostos pelos alunos da disciplina. Atratores que podem se materializar no cinismo de um texto, de um som ou de uma imagem que se ousa entonar. É o atrator que trama a linha por onde o movimento apreciativo de um aplicativo para uso educacional se dá junto à fronteira dos entres em direção à composição sensível da forma estética e hoje cada dia mais móvel e mais possível de encontrar Fetiches Visuais na composição. Registros autorais, portanto, dialógica e digitalmente compartilhados em uma outra dimensão de criação e produção midiáticas, a dimensão de uma inteligência que se conecta para dialogar com a estética de um Fetiche Visual também pedagógico- agora em forma de app.

\section{Referências}

Axt, M.; Martins, M. (2008). "Coexistir na diferença: De quando a formação em serviço pensamodos de habitar a sala de aula". In: TRINDADE, Iole Maria Faviero. (Org.). Múltiplas Alfabetizações e Alfabetismos. Porto Alegre: Editora da UFRGS, v. 1, p. 133-158.

Bakhtin, M.M. (2000). "Estética da Criação Verbal”. São Paulo: Martins Fontes.

Bakhtin, M. M. (1988) "Questões de Literatura e de Estética”. São Paulo, Unesp.

Boll, C.I. (2013) “A enunciação estética juvenil em vídeos escolares no youtube”. Porto Alegre, RS.

Brown. J. (2007) (org). "World Café”. São Paulo: Cultrix.

Canevacci, M. (2001) "Antropologia da Comunicação Visual”. Rio de Janeiro, DP\&A.

Canevacci, M. (2005). "Culturas Extremas: mutações juvenis nos corpos das metrópoles". Rio de Janeiro, DP\&A.

Canevacci, M. (2009) "A Comunicação Entre Corpos e Metrópoles", http:/www.usp.br/signosdoconsumo/artigos/artigo01_comunicacao_entre_corpos_m etropoles.pdf , Junho. 
VI Congresso Brasileiro de Informática na Educação (CBIE 2017)

Anais do XXIII Workshop de Informática na Escola (WIE 2017)

Canevacci, M. (2008) 'Fetichismos Visuais: corpos erópticos e metrópole comunicacional”. São Paulo, Ateliê Editorial.

Capra, F. (2005) “As Conexões Ocultas: ciência para uma vida sustentável”. São Paulo: Cultrix.

Jenkins, H. (2008) "Cultura da Convergência”. São Paulo: Aleph.

Lévy, P. A "Inteligência coletiva: por uma antropologia do ciberespaço". São Paulo: Edições Loyola, 1998.

Lévy, P. (2010) “Cibercultura”. São Paulo: Editora 34. 